\title{
Case study on the effects of smart energy community construction at Kanazawa seaside district in Yokohama
}

\author{
Satoshi Yoshida, ${ }^{1,}$, Satoru Sadohara ${ }^{1}$, Yuichi Ikuta $^{2}$, Ryota Kuzuki ${ }^{3}$, Toru Ichikawa ${ }^{3}$ \\ ${ }^{1}$ Yokohama National University, Yokohama, Japan \\ ${ }^{2}$ Japan Environment Systems, Tokyo, Japan \\ ${ }^{3}$ Tokyo Gas Corporations, Tokyo, Japan \\ * Corresponding author. Tel: +81 453394247, Fax:+81 453381016, E-mail: syoshida@ynu.ac.jp
}

\begin{abstract}
This research worked on the measure against $\mathrm{CO}_{2}$ reduction according to the characteristics of the area for the Kanazawa seaside area in Yokohama city. This area consists of a collective housing complexes and a minor scale industrial complex, and also locates a waste incineration plant, a wastewater treatment plant, and a sludge treatment facility. Having been chosen as a measure with the large amount of $\mathrm{CO}_{2}$ discharge reduction, it is the system which feeds into an incinerator the methane gas by carrying out mixed digestion of the kitchen garbage together with sewer sludge, and supply heat from a waste incineration factory through the transmission line. However, since this system has large initial cost for construction of transmission line, marginal abatement cost (MAC) for $\mathrm{CO}_{2}$ emission reduction is very as large as 166.16 [USD/CO $\mathrm{CO}_{2}$. Then, when the pay-back year of the transmission line was changed from 20 years to 31.5 years which is equivalent to $70 \%$ of legal durable years, MAC was reduced to 104.40 [USD/ $\mathrm{CO}_{2}$ ]. Moreover, when Non Energy Benefit (NEB) by system introduction, such as job creation and an environmental improvement of the area, was taken into consideration, MAC was greatly reduced to $-124.22\left[\mathrm{USD} / \mathrm{CO}_{2}\right]$.
\end{abstract}

Keywords: Exhaust heat from waste incineration plant, Solar energy, Digestion of sewage sludge mixed with kitchen garbage, $\mathrm{CO}_{2}$ reduction cost

\section{Introduction}

\subsection{Background and objectives of research}

As the countermeasures against the issues of global climate change, it is essential to reduce $\mathrm{CO}_{2}$ emissions from building sectors. To promote the reduction of $\mathrm{CO}_{2}$ emissions from building sectors, various countermeasures should be executed, not only for building sectors but also for the community. The Kyoto Protocol Target Achievement Plan was materialized in Japan in April, $2005^{[1]}$. Until then, main measures for the energy conservation such as heatinsulation and introduction of efficient equipments were implemented on individual buildings only. In this plan, measures for advance energy saving and low carbonation in the community were also specified in addition to the measures for individual buildings. For advance energy saving and low carbonation in the community, the mutual cooperation of various stakeholders of the community is indispensable. It is important to make the process which shares the target of energy saving and low carbonation, distributes profits impartially, and shares a risk equally within the community. Therefore, the objective of this study is to propose the measures for energy saving and low carbonation and examine the technique of presenting the effects (benefits) and risk (cost) clearly for Kanazawa seaside district in Yokohama city.

In this study, the countermeasures for the $\mathrm{CO}_{2}$ emission reduction in the community are focused. There are lots of options for the reduction of $\mathrm{CO}_{2}$ emissions at the community scale, such as PV's, solar thermal use, biomass, exhaust heat from waste incineration plant, and so on. But these options may not be suitably introduced anywhere. Thus, it is very important to recognize characteristics of the community to introduce the suitable countermeasure options. The case study area is Kanazawa seaside district in Yokohama City, Japan. 
The main purpose of this research is to determine the countermeasures for $\mathrm{CO}_{2}$ emission reduction which is appropriate for this community, and to analyze the cost effectiveness of these countermeasures.

\subsection{Study area}

The case study area is Kanazawa seaside district in Yokohama city. This district is reclaimed land with an area of 121.9ha ${ }^{[2]}$ where collective housings were sold in lots from around 1970. A railway runs through the center of this district to the south north. Residential area is located at the west side of the railway. At present, 7,500 households with the population of about 20,000 persons are living in this district ${ }^{[2]}$. It had been about 30 years after a sale in lots and now many housing complexes are aged and expected to be reconstructed and repaired. On the other hand, the east side of the railway is industrial complex area for middle to minor scale factories. There are some urban facilities in this area, such as a waste incineration plant, a sewage treatment plant, and a sludge treatment plant.

Kanazawa waste incineration plant incinerates about 300,000[t/year], and generates 130 [GWh/year] electric power by using exhaust heat of waste incineration [3]. Kanazawa wastewater treatment plant has treatment capacity of 265,900 $\left[\mathrm{m}^{3} / \mathrm{day}\right]^{[4]}$, and generates treated water (recycled waste water). Nanbu sludge treatment plant has treatment capacity of $14,700 \quad\left[\mathrm{~m}^{3} /\right.$ day $]$, and generates methane gas through digestion $\operatorname{tank}^{[5]}$. In addition, there are some office building, hotels, and the campus with the hospital of Yokohama City University.

In the road map for environment model city realization, Yokohama city government regards this area as an important area, and the Yokohama Green Valley project is in operation. The amount of $\mathrm{CO}_{2}$ emission from energy consumption in this area is assumed about 72,000 [t- $\mathrm{CO}_{2} /$ year]. About $60 \%$ of this emission is due to energy use in residential and business sectors.

\section{Countermeasures for smart energy community}

\subsection{Outline}

Figure 3 shows the smart energy network in the proposed area. Four stages were assumed as present condition (2010), the first stage (2015), the second stage (2020), and final stage (2025). Various countermeasures for each building promoted by Japanese government were executed,

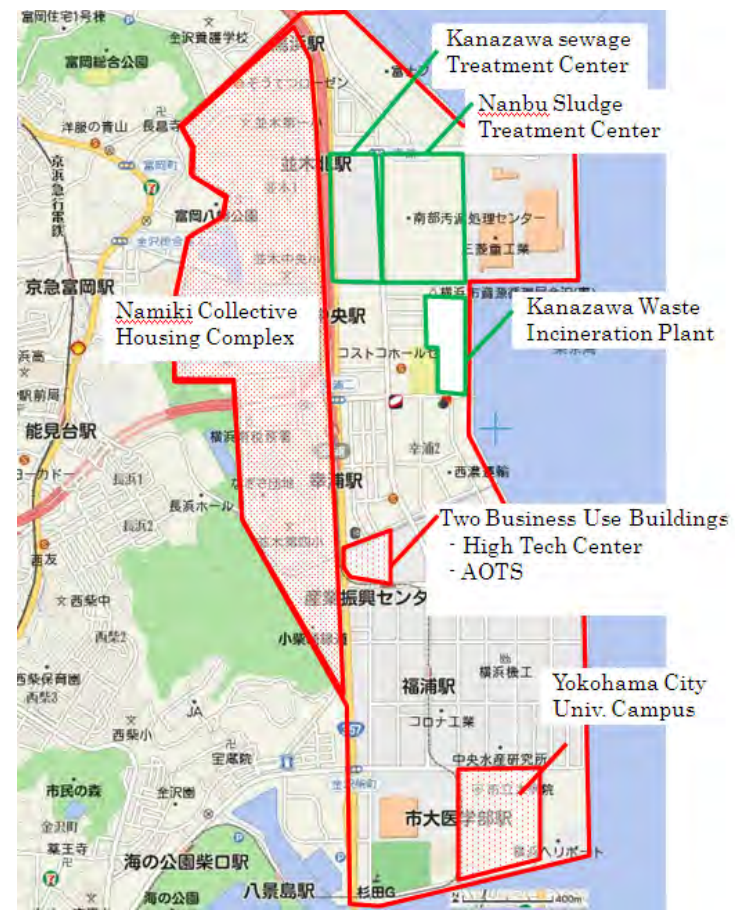

Figure 1 Kanazawa Seaside Area

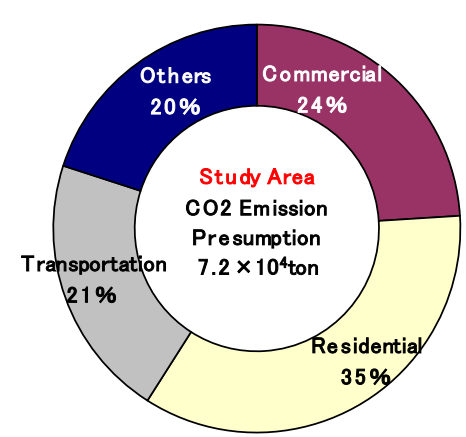

Figure 2 Estimated $\mathrm{CO}_{2}$ emission of Kanazawa seaside area and also the other measures for community scale were tried to be executed. While planning the smart energy network in this area as a whole, the effective use of urban facilities such as sewage treatment plant, waste incineration plant etc. were considered to have significant role. 
Table1 Present energy demand of subject buildings in this area

\begin{tabular}{|c|c|c|c|c|c|c|}
\hline & \multirow{2}{*}{$\begin{array}{c}\text { Total } \\
\text { Floor Area } \\
\mathrm{m}^{2}\end{array}$} & \multicolumn{4}{|c|}{ Demand (Present) } \\
\hline & & & $\begin{array}{l}\text { Electricity } \\
\text { GWh/year }\end{array}$ & $\begin{array}{l}\text { Heating } \\
\text { TJ/Year }\end{array}$ & $\begin{array}{l}\text { Cooling } \\
\text { TJ/Year }\end{array}$ & $\begin{array}{c}\text { Hot Water } \\
\text { TJ/Year }\end{array}$ \\
\hline Namiki Collective Housing Complex & House & 721,400 & 32.75 & 51.26 & 54.28 & 144.74 \\
\hline High-Tech Center & Office\&Hotel & 50,000 & 8.06 & 13.29 & 14.59 & 16.40 \\
\hline AOTS & Office\&Hotel & 12,000 & 1.73 & 4.78 & 3.36 & 10.78 \\
\hline Yokohama City University & Hospital\&University & 107,000 & 10.48 & 40.79 & 20.62 & 78.37 \\
\hline
\end{tabular}

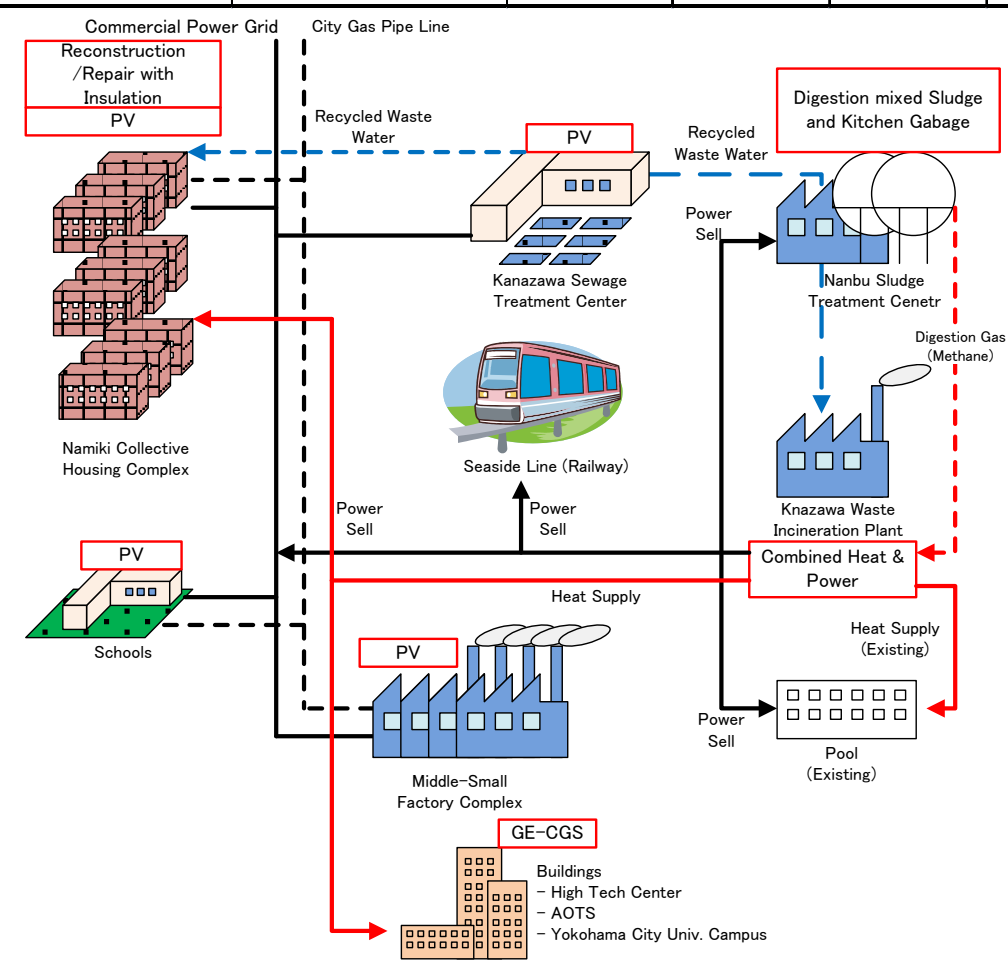

Figure3 Proposed smart energy network at Kanazawa seaside area

\subsection{Remote ownership of Photo Voltaic Panel}

In the Electricity Enterprises Law of Japan, the photovoltaic generation panels set up in places other than home are not permitted to be owned ${ }^{[6]}$. Therefore, families living in high-rise housing complexes don’t have their own roof and so cannot own the PV panels.

However, the development of smart meter and smart grid technology may solve this problem in near future. In this case study, the remote ownership of PV panels is proposed. People living in high-rise housing complexes can set up PV panels on the roof of factories, sewage treatment plant, and schools.

\subsection{Exhaust heat from waste incineration plant}

Today, exhaust heat from waste incineration is used for power generation. As incinerated waste includes wet kitchen garbage, the energy loss for the latent heat is caused. It was proposed that wet kitchen garbage to be collected separately and sent to sludge treatment plant for the methane generation by mixed digestion with sewage sludge. Generated methane is supplied to waste incineration plant as input to the boiler. Although the waste incineration plant supplies only electricity in the present condition, it was considered to supply heat also in this case study. If wet kitchen garbage is not incinerated, by rough estimation, calorific value of wet kitchen garbage and the energy loss for the latent heat decrease. When the kitchen garbage is not incinerated with other garbage, the quantity of heat generated by the 
incineration will decrease by a calorie of kitchen garbage. When the kitchen garbage is also included, an additional quantity of heat is required to evaporate its moisture content. Hence, if the additional quantity of heat is avoided then there will be no change of heat in total. Ministry of Land, Infrastructure, and Transportation in Japan had examined to increase the speed and the quantity of methane generation by digestion of sewage sludge mixed with slurry of kitchen garbage. This project was named LOTUS project ${ }^{[7]}$. Result of this LOTUS project was that it was possible to digest the kitchen garbage slurry which was equivalent to $13 \%$ of the sewage sludge, in addition two times of methane was generated compared to the case without the kitchen garbage slurry. Methane gas generation potential was calculated in the condition that the amount of mixed digested kitchen garbage was set half of the amount of kitchen garbage incinerated in the current condition because the cost for collecting the kitchen garbage separately was very large. Cost for the collection of kitchen garbage separately, removal of impurities contained in the garbage, and making of the garbage slurry were calculated.

\subsection{Cogeneration installation for business use}

Three large business use buildings were installed with GE-CGS in this study. Those buildings were hotels, offices, and university campus. Campus of Yokohama City University has also hospital building, and 700kW of GE-CGS was installed as part of ESCO project in 2009. High-Tech Center has hotel, office, and research laboratory, and 360kWof GE-CGS was installed in this study. AOTS is training facility with lodging for foreigners, and 90kW GECGS was installed in this study. This GE-CGS's were operated from 8:00am to 9:00pm.

The initial cost of CGS was considered as 2,000 USD per $\mathrm{kW}$, and the annual maintenance cost as 2.0 USD per $100 \mathrm{kWh}$.

\subsection{Thermal transmission network}

Heat supply transmission line was newly constructed in this district that connected sludge treatment plant, waste incineration plant, Namiki-collective housing complex area, and three larger business use buildings. Construction cost of the transmission line was considered, but the distribution pipes from the transmission line were not considered in the cost calculation.

This transmission line supply steam from waste incineration plant and sludge treatment plant as a heat load for Namiki- collective housing complex area, and three larger business use buildings. The quantity of heat that can be supplied from a garbage incineration plant and the amount of methane generated increased after the mixed digestion of sewage sludge and kitchen garbage were large enough. Therefore, it could provide all of the hot-water demand of the collective housing complexes, and the required heat demand of three business-use buildings.

\section{The result of $\mathrm{CO}_{2}$ Reduction effect}

Table 2 shows calculated reduction potential of $\mathrm{CO}_{2}$ emission by each countermeasure that had been considered in this case study. The amount of $\mathrm{CO}_{2}$ emission reduction by implementation of the countermeasures in each building was divided proportionally from statistical approach, such as population of the region, based on "Local government environmental report $2007^{[8] \text {, } . ~} \mathrm{CO}_{2}$ reduction potential through steam supply by transmission line was the largest of all measures. Of course, increment in the methane generation by the digestion of the mixture of raw sludge and kitchen garbage was also included in this measure. 
Table2 $\mathrm{CO}_{2}$ emission reduction potential

\begin{tabular}{|c|c|c|c|}
\hline & & Measures & $\begin{array}{l}\mathrm{CO}_{2} \text { Emission } \\
\mathrm{Reduction} \mathrm{P} \text { otential } \\
\text { [t- } \mathrm{CO} 2 / \text { year] }\end{array}$ \\
\hline (1) & [Residential] & Changes in Lifestyle & 454 \\
\hline (2) & [Commercial] & Changes in Workstyle & 131 \\
\hline (3) & [Residential] & Lighting Efficiency Improvements, etc & 565 \\
\hline (4) & [Residential] & $\begin{array}{l}\text { Heating and Cooling Efficiency } \\
\text { Improvements }\end{array}$ & 753 \\
\hline (5) & [Commercial] & Lighting Efficiency Improvements, etc & 311 \\
\hline (6) & [Commercial] & $\begin{array}{l}\text { Air Conditioning Equipment Efficiency } \\
\text { Improvement }\end{array}$ & 233 \\
\hline (7) & [Residential] & Introduce of HEMS & 444 \\
\hline (8) & [Commercial] & $\begin{array}{l}\text { Power and O ther E fficiency } \\
\text { Improvements }\end{array}$ & 109 \\
\hline (9) & [Commercial] & Use of Solar Thermal Energy & 870 \\
\hline
\end{tabular}

\begin{tabular}{|c|c|c|c|}
\hline & \multirow{2}{*}{\begin{tabular}{|l|} 
Measures \\
Commercial Cogeneration
\end{tabular}} & \multirow{2}{*}{$\begin{array}{l}\mathrm{CO}_{2} \text { Emission } \\
\mathrm{R} \text { eduction Potential } \\
\text { [t-C 02/year] }\end{array}$} \\
\hline (10) & [Commercial] & & \\
\hline (11) & [Commercial] & Introduce of BEMS & 19,344 \\
\hline (12) & $\begin{array}{l}\text { [J oint Commercial } \\
\text { and Residential] }\end{array}$ & $\begin{array}{l}\text { Incineration Plant Waste Heat and } \\
\text { Sludge Treatment P lant Digestion G as }\end{array}$ & 1,010 \\
\hline (13) & [Residential] & $\begin{array}{l}\text { Hous ehold appliances efficiency } \\
\text { improvements }\end{array}$ & 2,447 \\
\hline (14) & [Commercial] & P hotovoltaic power generation & 105 \\
\hline (15) & [R esidential] & P hotovoltaic power generation & 1,815 \\
\hline (16) & [Residential] & $\begin{array}{l}\text { Higher insulation in newly constructed } \\
\text { housing }\end{array}$ & 412 \\
\hline (17) & [Residential] & Improved existing insulation & 108 \\
\hline & & Total & 29,959 \\
\hline
\end{tabular}

\section{Cost-benefit Analysis}

\subsection{Additional cost curve for reduction of $\mathrm{CO}_{2}$ emission}

Based on the method of the marginal abatement cost (MAC) curve advocated by McKinsey ${ }^{[9]}$, the amount of $\mathrm{CO}_{2}$ discharge reduction in this area and the relation of that measure cost are analyzed. Subsequent analysis has adopted the analytical idea of MAC and the method in consideration of NEB which Kuzuki and others proposed ${ }^{[10]}$.

\subsubsection{Case of short pay-back time}

Figure 4 shows the case which calculated MAC based on short pay back year.

This short pay-back year refers to the value used by the Central Environment Council ${ }^{[11]}$, the Ministry of Environment, in order to calculate the $\mathrm{MAC}$ of $\mathrm{CO}_{2}$ emission reduction. It was about 3 to 5 years. In this case, as the initial cost including the MAC of photovoltaic, heat insulation repair of building and thermal transmission line was large enough; the MAC will also be higher. The average MAC of all measures was 237.11 [USD/t- $\mathrm{CO}_{2}$ ] for a year, and installation is difficult as long as there is no financial support of the subsidy etc.

\subsubsection{Case of long pay-back time}

On the other hand, since a building and a thermal transmission line were used over a long period of time, it could be thought that 3-5 years of the pay-back year was too short.

Then, $70 \%$ of legal durable years were re-set as the pay back years of each measure. Pay back years become longer and were from 20 years to maximum of 31.5 years.

Figure5 shows the calculated MAC based on these long pay back years. In the case of these long pay back years, the MAC per year decreased sharply, and the average MAC of all measures was 124.57 [USD/t- $\mathrm{CO}_{2}$ ] per year. Especially MAC of thermal transmission line reduced greatly to 104.40 [USD/t- $-\mathrm{CO}_{2}$ ] from 166.16 [USD/t-CO $\mathrm{CO}_{2}$ ], because pay back years changed from 20 years to 31.5 years. 


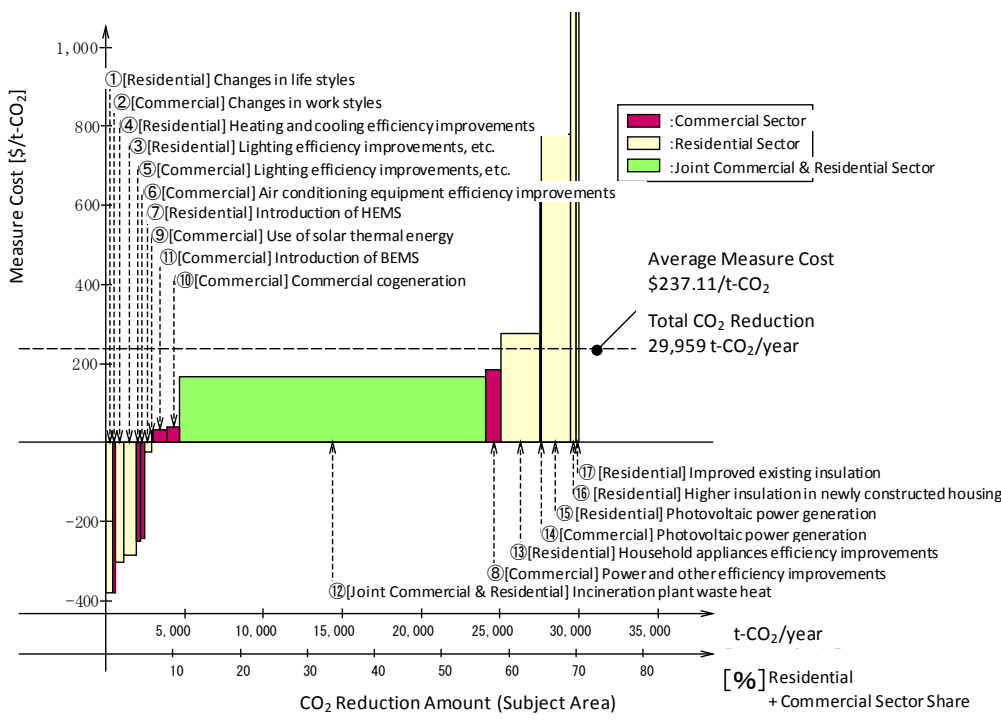

Figure4 Calculated MAC based on short disinvestment years

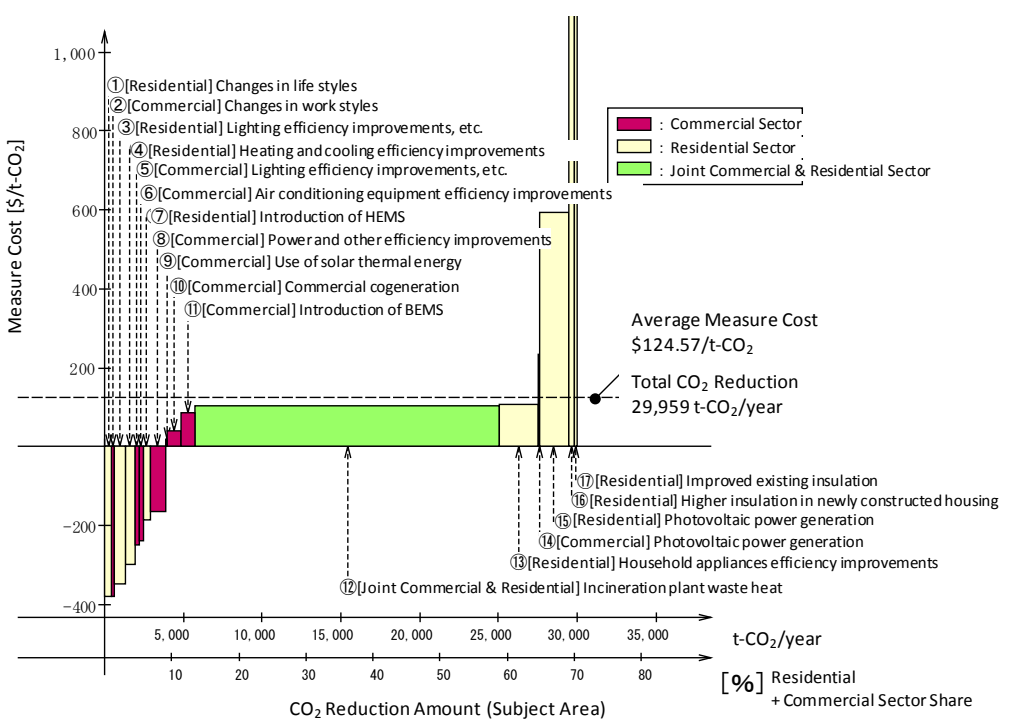

Figure 5 Calculated MAC based on long disinvestment years

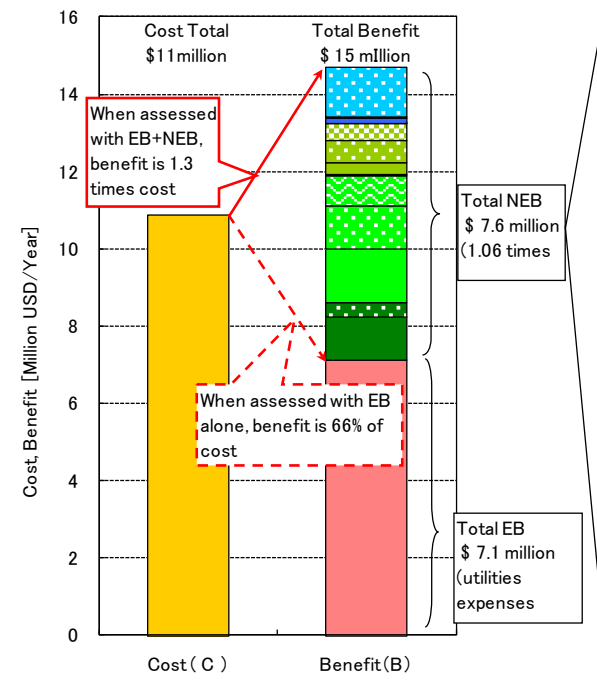

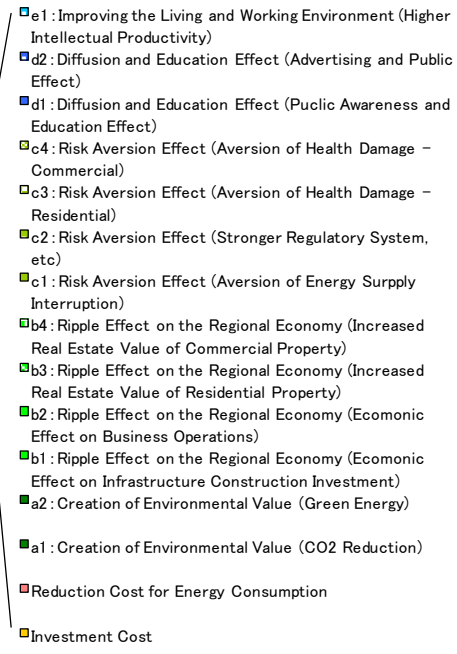

Figure6 B/C including NEB 


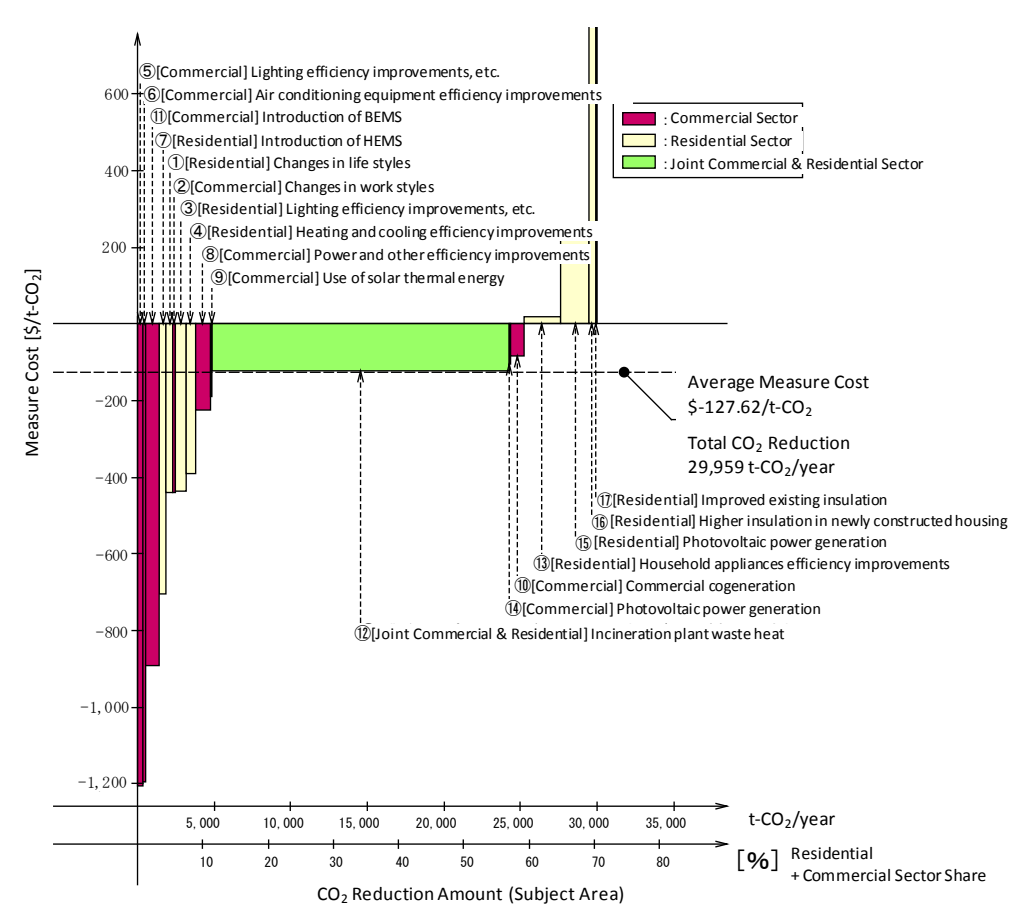

Figure7 Calculated MAC based on long disinvestment years in consideration of NEB

\subsection{Non-Energy Benefits}

These measures against $\mathrm{CO}_{2}$ emission reduction resulted the benefits of not only the decrement in energy cost but also the job creation, the environmental improvement of this area, etc. Then, NEB (Non-Energy Benefit) by the implementation of $\mathrm{CO}_{2}$ emission reduction measures in this area was computed based on the calculation method of the NEB which R. Kuzuki and others has advocated ${ }^{[4]}$.

Figure6 shows the relation between annual cost and NEB. The B/C including only direct benefits such as cut in fuel, lighting, and water cost by a measure was 0.66 . Then the $B / C$ including indirect benefits such as for example job creation etc., increased to 1.35.

Moreover, the calculation result was divided proportionally for each measure, and the MAC curve was created.

Figure7 shows the MAC curve in consideration of NEB. As a result of dividing indirect benefits proportionally for each measure against low carbon and re-creating a marginal abatement cost curve, $\mathrm{CO}_{2}$ reduction cost of each measure decreased greatly, and average measure cost reduced to $-127.62\left[\mathrm{USD} / \mathrm{t}-\mathrm{CO}_{2}\right]$.

\section{Conclusions}

From the results of this case study it became clear that the measures against low carbon of the community according to the characteristic of areas raised $\mathrm{CO}_{2}$ emission reduction potential. The effective countermeasures were thermal transmission line using methane gas produced by the digestion of mixture of sewer sludge and kitchen garbage sludge, and use surplus steam from waste incineration plant. It was also found that taking NEB into consideration improved $\mathrm{B} / \mathrm{C}$ greatly and increased feasibility. 


\section{References}

[1] Cabinet Secretariat Japan, Global Warming Prevention Headquarters, "Kyoto Protocol Target Achievement Plan,” April 2005

[2] Statistic Division of Ministry of Internal Affairs and Communications, National Census of Japan, 2005

[3] Waste and Recycle Division of Yokohama City, The amount of garbage incineration and power production according to incineration factory, 2008 http://www.city.yokohama.jp/me/pcpb/data/dat30.html\#syoukyakuryo(In Japanese)

[4] Yokohama City, Kanazawa Wastewater Treatment Plant (Pamphlet) http://www.city.yokohama.lg.jp/kankyo/gesui/centerinfo/06wtc/shiryo/pamph let.pdf(In Japanese)

[5] Yokohama City, Nanbu Sludge Treatment Center (Bio-Land Kanazawa) http://www.city.yokohama.lg.jp/kankyo/gesui/centerinfo/13src/ (In Japanese)

[6] Ministry of economy, trade and industry of Japan, Electricity Business Act, the last revision 2006 http://law.e-gov.go.jp/htmldata/S39/S39HO170.html(In Japanese)

[7] Ministry of Land, Infrastructure, and Transportation, "Lotus Project”, http://www.mlit.go.jp/kisha/kisha04/04/040917_html(In Japanese)

[8] Coalition of Japanese Local Governments for Environment Initiative and the Institute for Environmental Planning Inc., "2008 Local Government White Paper on the Environment,” Coalition of Local Governments for Environment Initiative Secretariat, May 2008

[9] McKinsey \& Company: "Pathways to a Low-Carbon Economy: Version 2 of the Global Greenhouse Gas Abatement Cost Curve,” January 2009

[10]R. Kuzuki, et al, Study on the Non-Energy Benefit (NEB) of Area-Wide Energy Utilization and Evaluation of the Marginal Abatement Cost , World Renewable Energy Congress 2011 - Sweden, Urban Energy (UE), 8-11 May 2011, Linköping, Sweden

[11]Central Environment Council, Global Environment Committee, Targets Reduction Scenario Subcommittee, Mid-term Report, June 2001 